\title{
The Clinical Use of Artificial Nerve Conduits for Digital Nerve Repair: A Prospective Cohort Study and Literature Review
}

\author{
Jörn A. Lohmeyer, M.D., 1,2 Frank Siemers, M.D., ${ }^{1}$ \\ Hans-Günther Machens, M.D., Ph.D., ${ }^{1,2}$ and Peter Mailänder, M.D., Ph.D. ${ }^{1}$
}

Tubulization as an alternative to autologous nerve grafting successfully bridges relatively short nerve gaps. Digital nerve lesions are ideal for clinical outcome studies, but only a few data have been published so far. We are presenting our clinical experiences based on a review of the outcome and techniques in the current literature. Fifteen digital nerve lesions in 14 patients have been overcome by interpositional grafting of a hollow collagen I conduit. A follow-up of 12 months could be guaranteed in 12 cases. The mean nerve gap was $12.5 \pm 3.7 \mathrm{~mm}$. Four out of 12 patients, assessed 12 months postoperatively, showed excellent sensibility (S4). Five patients achieved good sensibility, one poor, and two no sensibility. Our results confirm tubulization as one possible technique in nerve reconstruction. However, the indication has to be set carefully, and the operation still requires solid microsurgical skills, especially for proper handling and debridement of the severed nerve endings.

KEYWORDS: Digital nerve, nerve tube, nerve reconstruction, collagen, clinical study

Nerve injuries are common in trauma surgery and appear more frequently if the upper extremity is affected. ${ }^{1}$ Nerves are affected in $\sim 10 \%$ of all hand injuries that require surgical treatment. ${ }^{2}$ The consequences may be numbness and impairment of motor function. After repair, an intensive period of rehabilitation is required. Sick leave and sometimes the need for a change in profession and partial or even permanent total disability may have severe economic impact on the patient and society. ${ }^{3,4}$ If the upper extremity is affected, the most frequently injured nerves are the proper and common digital nerves, followed by the median and ulnar nerves. ${ }^{2,5}$ Complete transection of a peripheral nerve requires reconstruction of the continuity from proximal and distal nerve stump. The gold standard for nerve injuries that cannot be overcome by direct tensionless coaptation is the nerve autograft. ${ }^{6}$ Primary repair by endto-end coaptation can be performed in $\sim 82 \%$ of the cases. ${ }^{7}$ Thus usually $18 \%$ require nerve reconstruction by means of grafting or tubulization. In some cases, endto-side neurorrhaphy can be an alternative. ${ }^{8}$

Digital nerve lesions are ideal for clinical outcome studies because results are easy to compare, but only a few data of nerve reconstruction with artificial hollow
${ }^{1}$ Plastic Surgery, Hand Surgery, Burn Unit, University Hospital of Schleswig-Holstein, Campus Luebeck; ${ }^{2}$ Plastic Surgery and Hand Surgery, Klinikum rechts der Isar, Technical University Munich, Munich, Germany.

Address for correspondence and reprint requests: Jörn Lohmeyer, M.D., Klinikum rechts der Isar, Technical University Munich, Klinik und Poliklinik für Plastische Chirurgie und Handchirurgie, Ismaninger
Str. 22, Munich 81675, Germany (e-mail: lohmeyer@1rz.tum.de). J Reconstr Microsurg 2009;25:55-62. Copyright (C) 2009 by Thieme Medical Publishers, Inc., 333 Seventh Avenue, New York, NY 10001, USA. Tel: +1(212) 584-4662.

Received: February 17, 2008. Accepted: July 24, 2008. Published online: November 26, 2008.

DOI 10.1055/s-0028-1103505. ISSN 0743-684X. 

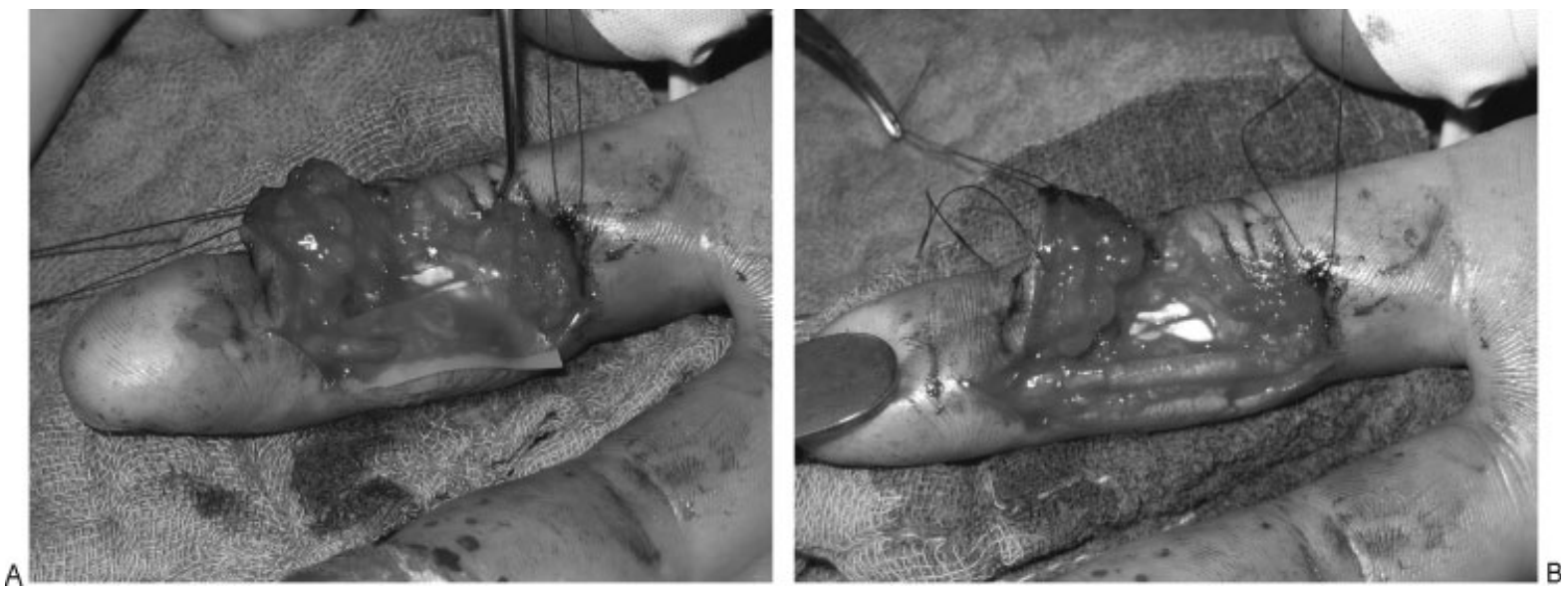

Figure 1 Intraoperative images after $(A)$ debridement and $(B)$ implantation of the collagen I nerve conduit at the medial phalanx of the right index (patient 13).

conduits have been published so far. ${ }^{9-14} \mathrm{We}$ are presenting our clinical experiences on the background of the current literature.

\section{MATERIAL AND METHODS}

From July 2004 to November 2006, 15 nerve lesions in 14 patients were reconstructed by using tubulization technique in our clinic. In the same period, 140 digital nerves were subjected to tensionless end-to-end coaptation. One patient required autologous nerve grafting due to an extended gap length. The study was approved by the local review board. We restricted the indication for tubulization to palmar- and digital-sensitive nerves distal to the wrist. Collagen I conduits were used (NeuraGen; Integra LifeSciences, Plainsboro, NJ), which are available in a maximum length of $30 \mathrm{~mm}$. The semipermeable tubes are made from bovine tendon and can be maintained in different diameters ranging from 1.5 to $7 \mathrm{~mm}$. In our study, all patients received conduits with an internal diameter of $2 \mathrm{~mm}$. In a moist state, wall thickness is rather precisely $0.5 \mathrm{~mm}$. Conduits are soft, pliable, and completely degraded by 36 months. ${ }^{15}$ All patients were operated on by microsurgically trained plastic surgeons. Figure 1 shows a clinical example.

The cause of nerve damage was traumatic in 14 cases and iatrogenic in 1 case (Table 1). The mechanism was mostly a cut injury by glass (7 of 15), knives or scissors (5 of 15), or a steel sheet (1 of 15). In one case, it was based on a circular saw accident, and in another, a drilling accident. In five cases, we achieved primary reconstruction. Another nine were objects of secondary reconstruction 1 week up to 37 months after the initial injury. In those two cases that were reconstructed 19 and 37 months after the injury, the patients attended our

Table 1 Patient Overview of All Cases with Nerve Reconstruction by Means of Tubulization

\begin{tabular}{|c|c|c|c|c|c|c|c|c|}
\hline Patient & Age & Gender & Occupation & $\begin{array}{l}\text { Mechanism } \\
\text { of Injury }\end{array}$ & $\begin{array}{l}\text { Primary or } \\
\text { Delayed } \\
\text { Surgery }\end{array}$ & $\begin{array}{l}\text { Nerve } \\
\text { (N1-N10) }\end{array}$ & $\begin{array}{l}\text { Gap } \\
\text { Length/ } \\
\mathrm{mm}\end{array}$ & $\begin{array}{l}\text { Distance Proximal } \\
\text { Suture to } \\
\text { Fingertip/mm }\end{array}$ \\
\hline 1 & 12 & $\mathrm{~F}$ & Student & Mirror fragment & $19 \mathrm{mo}$ & N8/9 & 18 & 115 \\
\hline 2 & 38 & $\mathrm{~F}$ & Homemaker & Broken glass plate & $37 \mathrm{mo}$ & N1 & 13 & 47 \\
\hline 3 & 13 & M & Student & Window grate & 4 wk & N10 & 8 & 60 \\
\hline 4 & 25 & M & Craftsman & Glass bottle fragment & Primary & N3 & 15 & 110 \\
\hline 5 & 66 & $\mathrm{~F}$ & Pensioner & Knife stab & $3 w k$ & N5 & 6 & 58 \\
\hline 6 & 22 & M & Student at university & Broken jar & $1 \mathrm{wk}$ & N2 & 12 & 50 \\
\hline 7 & 66 & M & Pensioner & Circular saw & Primary & N3 & 10 & 80 \\
\hline 8 & 58 & $\mathrm{~F}$ & Hairdresser & latrogenic pulley splitting & $4 \mathrm{mo}$ & N1 & 12 & 62 \\
\hline 9 & 36 & M & Dental technician & Drilling machine & Primary & N4 & 18 & 106 \\
\hline 10 & 42 & M & Engineer & Cardboard cutter & 4 wk & N3 & 15 & 58 \\
\hline 11 & 57 & M & Mechanical engineer & Stab with scissors & $7 w k$ & N4 & 16 & 63 \\
\hline 12 & 13 & M & Student & Sword blade & Primary & N4 & 9 & 95 \\
\hline 13 & 23 & M & Laborer & Steel sheet & Primary & N4 & 12 & 45 \\
\hline \multirow[t]{2}{*}{14} & \multirow[t]{2}{*}{62} & \multirow[t]{2}{*}{ M } & \multirow[t]{2}{*}{ Barkeeper } & \multirow[t]{2}{*}{ Glass fragment } & \multirow[t]{2}{*}{$1 \mathrm{mo}$} & N1 & 12 & 60 \\
\hline & & & & & & N2 & 14 & 60 \\
\hline
\end{tabular}


clinic for the first time less than a month before surgery. No patient suffered from alcoholism, diabetes, neuropathia, or collagenous diseases.

Twelve patients were available for follow-up. One patient died and in one case the patient's current address could not be obtained (patients 13 and 14). The mean age of the follow-up cohort was 38 years (range, 12 to 66 years). The average gap length was $12.7 \pm 3.7 \mathrm{~mm}$ (range, 6 to $18 \mathrm{~mm}$ ). Wound contamination was absent or minimal in all cases. The distance of the proximal suture line to the distal fingertip was on average $71 \mathrm{~mm}$ (45 to $115 \mathrm{~mm}$ ).

The operating microscope was used in all operations. The repair of concomitant injuries of the hand as well as exposure of the severed nerve ends is performed under tourniquet control. It has to be released (followed by meticulous hemostasis) before insertion of the nerve ends into the conduit to prevent bleeding into the lumen because the formation of a blood clot inside the tube is detrimental to nerve regeneration. After proper debridement, proximal and distal nerve endings were inserted into the conduit with an overlap of $\sim 2 \mathrm{~mm}$. To evacuate the conduit from potentially remaining blood clots, it was rinsed with normal saline after each suture, which was performed with one 10-0 nylon U suture at both sides. We decided to administer single-shot $1.5 \mathrm{~g}$ cefuroxime intravenously to prevent infection. Immobilization of the adjacent joints was assured for 14 days. Sensibility was assessed using static and moving twopoint discrimination $\left(\mathrm{s}^{-}, \mathrm{m} 2 \mathrm{PD}\right)$ and monofilament testing 3, 6, and 12 months postoperatively at the regularly scheduled outpatient visits. For two-point discrimination, we used the Greulich star. Sensibility testing was performed without digital nerve block for the intact nerve because results were not expected to differ. ${ }^{13}$

\section{RESULTS}

No preoperative complications were seen in all patients with nerve conduit implantation. All wounds could be closed primarily without tension to cover the conduits. No wound infection or conduit extrusion was seen. Four out of 12 patients, assessed 12 months postoperatively, showed excellent sensibility with s2PD of $\leq 7 \mathrm{~mm}$ (S4). Five patients achieved good sensibility (s2PD $\leq 15 \mathrm{~mm}$, $\mathrm{S} 3+)$, one poor (s2PD $>15 \mathrm{~mm}, \mathrm{~S} 2)$, and two no sensibility (S0; Table 2).

One patient complained of persisting mild hyperesthesia. Three out of 15 patients complained of some temporary foreign body sensation in the area of the implant, which was persistent in one case for $>6$ months (patient 1). In the latter, preoperatively existing neuroma pain improved considerably, although numbness remained. Despite the numbness and mild hyperesthesia, this patient was rather satisfied by the clinical result and did not wish operative revision. No
Table 2 Results of s2PD 3, 6, and 12 Months

Postoperatively*

\begin{tabular}{|c|c|c|c|c|c|}
\hline \multirow[b]{2}{*}{ Patient } & \multicolumn{3}{|c|}{$\begin{array}{c}\text { Static Two-Point- } \\
\text { Discrimination/mm }\end{array}$} & \multirow{2}{*}{$\begin{array}{l}\text { Protective } \\
\text { Sensibility }\end{array}$} & \multirow[b]{2}{*}{ So-S4 } \\
\hline & $3 \mathrm{mo}$ & $6 \mathrm{mo}$ & $12 \mathrm{mo}$ & & \\
\hline 1 & $>15$ & $>15$ & $>15$ & No & So \\
\hline 2 & 8 & 7 & 7 & Yes & S3+ \\
\hline 3 & 6 & 6 & 5 & Yes & S4 \\
\hline 4 & $>15$ & 6 & 4 & Yes & S4 \\
\hline 5 & 6 & 4 & 4 & Yes & S4 \\
\hline 6 & $>15$ & 15 & 15 & Yes & S3+ \\
\hline 7 & $>15$ & 10 & 10 & Yes & S3+ \\
\hline 8 & 12 & 10 & 9 & Yes & S3+ \\
\hline 9 & $>15$ & $>15$ & $>15$ & No & so \\
\hline 10 & 10 & 7 & 7 & Yes & S3+ \\
\hline 11 & $>15$ & $>15$ & $>15$ & Yes & S2 \\
\hline 12 & 15 & 6 & 6 & Yes & S4 \\
\hline
\end{tabular}

*Immediately after surgery, m2PD was tested $>15 \mathrm{~mm}$ in all patients.

other patient complained of hyperesthesia. In another case of neuroma excision, 37 months after injury nerve reconstruction by means of tubulization helped extinguish neuroma pain and to restore good sensibility (patient 2).

We did not observe differences in injury-related working ability or wound healing in the cases of tubulization compared with end-to-end nerve coaptation. In some cases, it may be hard to distinguish foreign body sensation from induration caused by scarring.

\section{DISCUSSION}

The tension-free nerve coaptation is the method of choice for reconstruction after complete nerve transection. Secondary reconstruction with retraction of the nerve endings, tissue loss due to trauma, or necessary debridement can lead to extended nerve gaps that require alternative surgery. Today, the gold standard is the autologous nerve graft, but graft harvesting usually causes some degree of donor site morbidity and the number of nerves suitable for transplantation is strictly limited. For certain indications, artificial nerve conduits have become a possible alternative to nerve grafting. But limited data and differences in functional evaluation render direct comparison of results difficult. The most standardized and comparable in terms of lesion site and methods of evaluation seem to be the digital nerves of the hand. Results for nerve reconstruction by tubulization are often promising, although literature on clinical outcome is limited. The aim of our study is to contribute our clinical experiences and to outline comparable data from the current literature.

A few studies exist covering the use of biodegradable artificial hollow nerve conduits for digital nerve 
repair. In 1990, Mackinnon and Dellon were the first to report on 15 digital nerve lesions being reconstructed with hollow polyglactin conduits. ${ }^{13}$ Weber and colleagues described, in the biggest study so far, the use of the same material in 62 digital nerve reconstructions, of which 46 could be followed up. ${ }^{14}$ In the same year, Casañas reported on 17 secondary reconstructed nerves with subjective sensory improvement in every case. ${ }^{11}$ In 2005 Battiston et al reported on 19 and Bertleff et al on 21 digital nerves being reconstructed by tubulization, the latter using the only transparent tube, made from poly(DL-lactid- $\varepsilon$-caprolactone). ${ }^{9,10}$ One year later, Dellon and Maloney put forward another two cases of digital nerve repair, again with polyglactin conduits. ${ }^{15}$ Table 3 presents an overview on these studies. Taras et al described the use of collagen I conduits for digital nerve repair among others, but neither the precise number nor outcome was mentioned. However, the clinical impression was reported to be very positive. ${ }^{16}$ The results of this study are yet to be published. Figure 2 shows the clinically approved collagen I, polyglactin, and poly(DL-lactid- $\varepsilon$-caprolactone) conduits.

A variety of alternatives to hollow biodegradable nerve conduits have been tested in experimental or clinical settings. Nonresorbable conduits made of silicone, Teflon, or Polysulfone can lead to secondary nerve compression and usually prevent nutrient diffusion into the lumen. Experimental studies displayed worse results compared with degradable materials, and the clinical application led to nerve compression with the need for secondary removal. ${ }^{17-19}$ Autologous materials such as arteries and veins, some in combination with muscle inlays, have been assessed clinically. The use of vein grafts requires a donor site. Compared with arteries for peripheral nerve repair, donor site morbidity is rather minor and subcutaneous veins are rather redundant. But the tendency to collapse is high, and the chances to maintain an open inner space are low. Scarring of the surrounding tissue might subsequently prevent the vein to expand later when the nerve growth cone is passing the nerve gap. ${ }^{20-22}$ Another way to stabilize the lumen is to fill it with a solid inner matrix like muscle or collagen sponges. Clinical results may be promising, but tissue transfer usually requires some degree of donor site morbidity. ${ }^{23}$ However, artificial hollow nerve conduits can be constructed to maintain the appropriate degree of mechanical strength to optimize the time needed for resorption and to strictly avoid any donor site morbidity.

\section{Surgical Technique}

There is a certain degree of consensus on the surgical technique for tubulization. The overlap of nerve and conduit has to be long enough to secure coaptation and usually measures up to 2 to $5 \mathrm{~mm}^{10,13}$. It may be necessary to fix the nerve ends with two separate $U$ sutures at each end to achieve proper positioning of the nerve ends within the lumen. To prevent blood clot formation within the conduit, the tourniquet has to be released before implantation, and the lumen should be flushed afterward. Either normal or heparinized saline or autologous serum can be used. ${ }^{13,14}$ No evidence indicates a beneficial use of one over the other. Most authors agreed to exclude patients with diabetes, peripheral neuropathia, vasculitis, or alcoholism for study purposes. Antibiotic treatment was usually given in a single shot before $^{10}$ or for 1 week after surgery. ${ }^{14}$

The need for standardized immobilization of the joints at the site of nerve regeneration was demanded by all authors (except Taras) for a period from 10 days to 3 weeks. ${ }^{10,13}$ In our clinical study, we defined 14 days of immobilization. However, in previous animal experiments with tubulization of the sciatic nerve in the rat without postoperative immobilization, tube dislocation could not be observed in a single case. ${ }^{24}$

\section{Functional Outcome}

Good functional comparison after digital nerve reconstruction can be drawn by assessing sensibility and physical complaints. Most authors survey static and moving two-point discrimination (s2PD, m2PD); some use monofilament testings. Surveys often rely on the criteria set by the Nerve Injuries Committee of the British Medical Research Council, as modified by Mackinnon and Dellon. ${ }^{25}$ It is a helpful tool to give a standardized base that is needed for comparison. However, some studies do rely on other classifications or do not specify the results in a comparable state. ${ }^{10,11,16}$ The classification into very good (or excellent), good, and poor results is inconsistent. Some authors value s2PD of 7 to $15 \mathrm{~mm}(\mathrm{~S} 3+)$ as good, ${ }^{13,14}$ some even as very good or excellent. ${ }^{9}$ Accordingly, S3 is either valued as poor or good, depending on the observer. We decided to rely on the former definition. The outcome of this study showed excellent or good sensibility after nerve reconstruction by tubulization in 9 of 12 cases. Only two patients claimed no recovery of sensibility. Eleven of 12 patients were pain free, and only one suffered from mild hyperesthesia. No patient asked for secondary revision. Our findings support the clinical impression in reported studies that this method was regarded positively, being about equal to standard methods of end-to-end repair or grafting.

Weber's group conducted the first prospective, randomized multicenter study on biodegradable tubes. All patients with complete nerve transection were included. ${ }^{14}$ They even found favorable results in the use of conduits in nerve gaps of $\leq 4 \mathrm{~mm}$ in comparison with end-to-end coaptation. The authors always left a minimum space of $5 \mathrm{~mm}$ between nerve ends in those cases in which there was only a 0 - to $4-\mathrm{mm}$ nerve tissue defect. For nerve gaps of $\geq 8 \mathrm{~mm}$, tubulization again rendered 


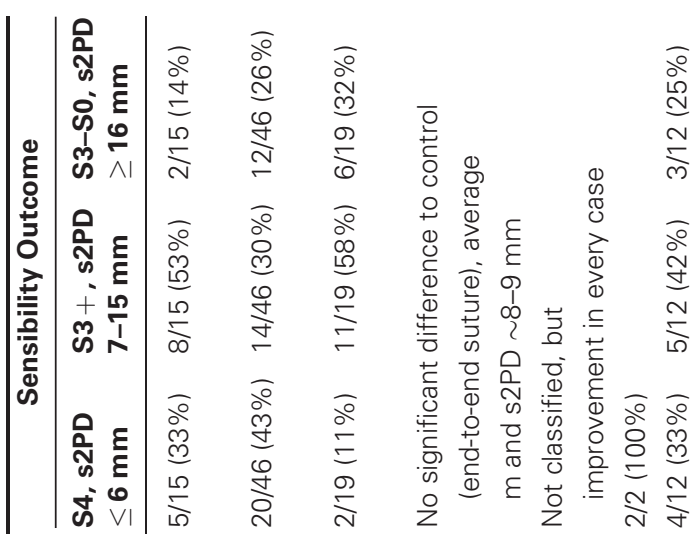

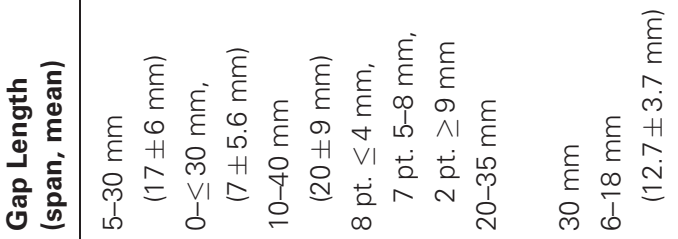

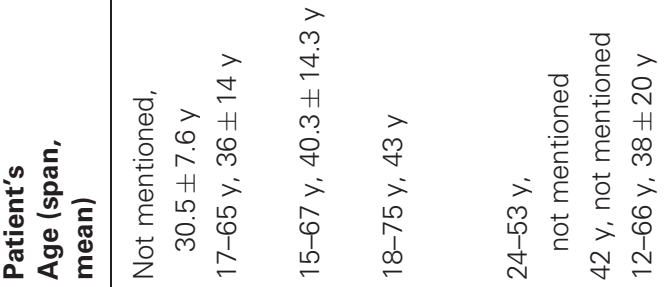

은

온

i்

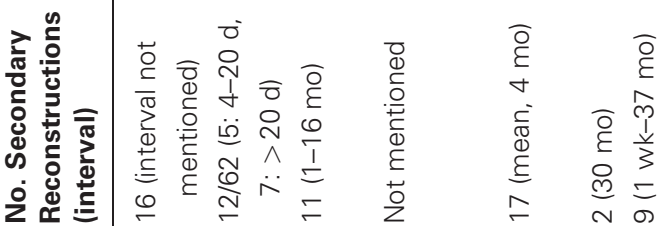

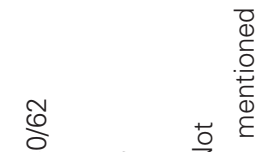

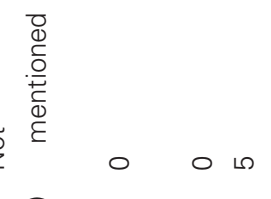

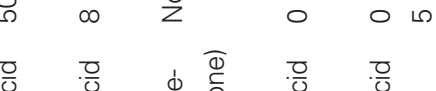

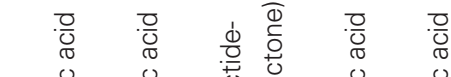




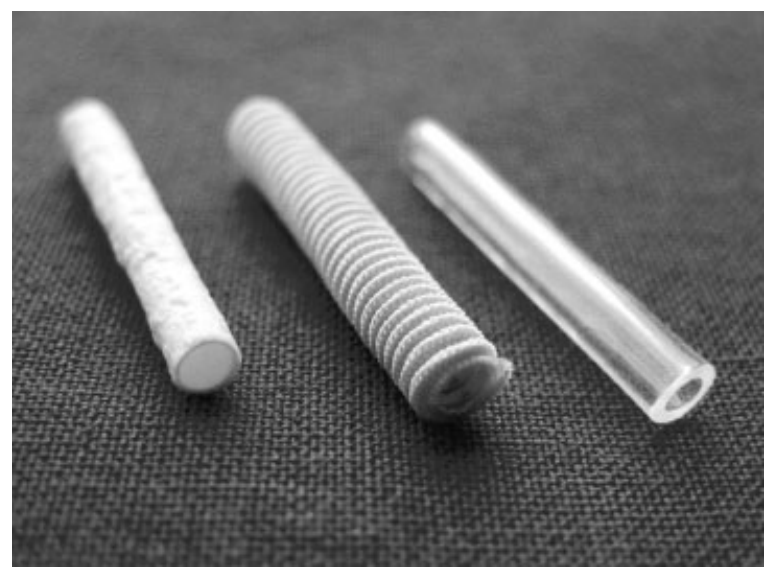

Figure 2 Left to right: Collagen I conduit (NeuraGen; Integra LifeSciences, Plainsboro, NJ); polyglycolic acid conduit (Neurotube; Synovis, Micro Companies Alliance, Birmingham, $A L)$; poly(DL-lactid-e-caprolactone) conduit (Neurolac; Polyganics BV, Groningen, The Netherlands).

better sensibility than nerve grafting. But, overall, the results showed no significant difference between tubulization and standard repair as a whole. The better results for nerve conduits compared with end-to-end neurorrhaphy in short nerve gaps have also been reported by Lundborg et al in lesions of the median and ulnar nerve. ${ }^{17}$ The short empty space intentionally left between two nerve stumps could allow proper orientation of the regenerating axons. In contrast, by direct suture, axon regeneration might be mismatched by the forced orientation given by the surgeon. ${ }^{26}$

The shorter the nerve gap, the better the expected outcome for reconstruction. ${ }^{14}$ The maximum gap length to be bridged by tubulization should not exceed $30 \mathrm{~mm}$ because beyond that, regeneration capacity clearly deteriorates.

Nerve tubes have been used for primary ${ }^{9,14}$ as well as secondary reconstruction. ${ }^{9,11,13,14,27}$ In the case of preexisting neuroma formation, Mackinnon and Dellon reported on excellent or good pain relief in seven of eight cases. ${ }^{13}$ Worse outcome is reported if nerve damage was caused by crush or avulsion injury. ${ }^{14}$ Deterioration of clinical results may be caused by insufficient initial trimming of the nerve ends. The use of nerve conduits instead of end-to-end coaptation or grafting might improve the willingness for extended debridement and thereby reduce intraneural scar formation.

\section{CONCLUSIONS}

Today, the use of hollow artificial nerve conduits is limited to nerve gaps up to $30 \mathrm{~mm}$. Results deteriorate with extended gap length. Because a nerve conduit can be used instead of end-to-end coaptation or grafting, the surgeon may be more willing to debride the nerve endings and thus improve function by diminishing intraneural scarring. For certain indications, nerve conduits have become a useful tool to avoid donor site morbidity associated with autologous nerve grafting. However, published data on this technique are still limited, and further studies are needed to explore all assets and drawbacks.

\section{REFERENCES}

1. Noble J, Munro CA, Prasad VS, Midha R. Analysis of upper and lower extremity peripheral nerve injuries in a population of patients with multiple injuries. J Trauma 1998;45:116-122

2. Renner A, Cserkuti F, Hankiss J. Late results after nerve transplantation on the upper extremities. Handchir Mikrochir Plast Chir 2004;36:13-18

3. Rosberg HE, Carlsson KS, Hojgard S, Lindgren B, Lundborg G, Dahlin LB. Injury to the human median and ulnar nerves in the forearm-analysis of costs for treatment and rehabilitation of 69 patients in southern Sweden. J Hand Surg [Br] 2005;30:35-39

4. Jaquet JB, Luijsterburg AJ, Kalmijn S, Kuypers PD, Hofman A, Hovius SE. Median, ulnar, and combined median-ulnar nerve injuries: functional outcome and return to productivity. J Trauma 2001;51:687-692

5. McAllister RM, Gilbert SE, Calder JS, Smith PJ. The epidemiology and management of upper limb peripheral nerve injuries in modern practice. J Hand Surg [Br] 1996; 21:4-13

6. Berger A, Millesi H. Nerve grafting. Clin Orthop Relat Res 1978:49-55

7. de Medinaceli L, Prayon M, Merle M. Percentage of nerve injuries in which primary repair can be achieved by end-toend approximation: review of 2,181 nerve lesions. Microsurgery 1993;14:244-246

8. Beris A, Lykissas M, Korompilias A, Mitsionis G. End-to-side nerve repair in peripheral nerve injury. J Neurotrauma 2007; 24:909-916

9. Battiston B, Geuna S, Ferrero M, Tos P. Nerve repair by means of tubulization: literature review and personal clinical experience comparing biological and synthetic conduits for sensory nerve repair. Microsurgery 2005;25:258-267

10. Bertleff MJ, Meek MF, Nicolai JP. A prospective clinical evaluation of biodegradable Neurolac nerve guides for sensory nerve repair in the hand. J Hand Surg [Am] 2005;30:513518

11. Casañas J, Serra J, Orduna M, García-Portabella M, Mir X. Repair of digital sensory nerves of the hand using polyglycolic acid conduits. J Hand Surg [Br ] 2000;25B(suppl 1):44

12. Lohmeyer J, Zimmermann S, Sommer B, Machens HG, Lange T, Mailander P. Bridging peripheral nerve defects by means of nerve conduits. Chirurg 2007;78:142-147

13. Mackinnon SE, Dellon AL. Clinical nerve reconstruction with a bioabsorbable polyglycolic acid tube. Plast Reconstr Surg 1990;85:419-424

14. Weber RA, Breidenbach WC, Brown RE, Jabaley ME, Mass DP. A randomized prospective study of polyglycolic acid conduits for digital nerve reconstruction in humans. Plast Reconstr Surg 2000;106:1036-1045

15. Dellon AL, Maloney CT Jr. Salvage of sensation in a halluxto-thumb transfer by nerve tube reconstruction. J Hand Surg [Am] 2006;31:1495-1498 
16. Taras JS, Nanavati V, Steelman P. Nerve conduits. J Hand Ther 2005;18:191-197

17. Lundborg G, Rosen B, Dahlin L, Holmberg J, Rosen I. Tubular repair of the median or ulnar nerve in the human forearm: a 5-year follow-up. J Hand Surg [Br] 2004;29:100 107

18. Braga-Silva J. The use of silicone tubing in the late repair of the median and ulnar nerves in the forearm. J Hand Surg [Br] 1999;24:703-706

19. Merle M, Dellon AL, Campbell JN, Chang PS. Complications from silicon-polymer intubulation of nerves. Microsurgery 1989;10:130-133

20. Tang JB, Shi D, Zhou H. Vein conduits for repair of nerves with a prolonged gap or in unfavourable conditions: an analysis of three failed cases. Microsurgery 1995;16:133-137

21. Chiu DT, Strauch B. A prospective clinical evaluation of autogenous vein grafts used as a nerve conduit for distal sensory nerve defects of $3 \mathrm{~cm}$ or less. Plast Reconstr Surg 1990;86:928-934
22. Walton RL, Brown RE, Matory WE Jr, Borah GL, Dolph JL. Autogenous vein graft repair of digital nerve defects in the finger: a retrospective clinical study. Plast Reconstr Surg 1989;84:944-949

23. Battiston B, Tos P, Cushway TR, Geuna S. Nerve repair by means of vein filled with muscle grafts I. Clinical results. Microsurgery 2000;20:32-36

24. Lohmeyer JA, Shen ZL, Walter GF, Berger A. Bridging extended nerve defects with an artificial nerve graft containing Schwann cells pre-seeded on polyglactin filaments. Int J Artif Organs 2007;30:64-74

25. Mackinnon SE, Dellon AL. Surgery of the Peripheral Nerve. New York, NY: Thieme Medical Publishers; 1988:637

26. Dahlin LB, Lundborg G. Use of tubes in peripheral nerve repair. Neurosurg Clin N Am 2001;12:341-352

27. Dellon AL. Polyglycolic acid conduits for digital nerve reconstruction. Plast Reconstr Surg 2001;107:1924-1925 